\title{
Transcranial Magnetic Stimulation (TMS) Safety with Respect to Seizures: A Literature Review
}

This article was published in the following Dove Press journal:

Neuropsychiatric Disease and Treatment

\section{Debra J Stultz \\ Savanna Osburn (DD \\ Tyler Burns \\ Sylvia Pawlowska-Wajswol \\ Robin Walton}

Stultz Sleep \& Behavioral Health, Barboursville, WV 25504, USA
Correspondence: Debra J Stultz

Stultz Sleep \& Behavioral Health, 6171

Childers Road, Barboursville, WV 25504,

USA

Tel + I 304-733-5380

Fax + I 304-733-5796

Email wvsleepdoc@stultzsleep.com

\begin{abstract}
Transcranial magnetic stimulation is an increasingly popular FDA-approved treatment for resistant depression, migraines, and OCD. Research is also underway for its use in various other psychiatric and medical disorders. Although rare, seizures are a potential adverse event of TMS treatment. In this article, we discuss TMS-related seizures with the various coils used to deliver TMS, the risk factors associated with seizures, the differential diagnosis of its presentations, the effects of sleep deprivation and alcohol use on seizures, as well as seizure risks with protocols for traditional TMS, theta-burst stimulation, and accelerated TMS. A discussion is presented comparing the potential risk of seizures with various psychotropic medications versus TMS. Included are case reports of TMS seizures in the child/adolescent patient, bipolar disorder patients, patients with a history of a traumatic brain injury, and those with epilepsy. Reports are also shared on TMS use without seizures in patients with a history of head injuries and TMS's continued use if patients have a seizure during their TMS treatment. Findings generated in this review suggest the following. Seizures, if present, are usually selflimiting. Most treatment recommendations for TMS-related seizures are supportive in nature. The risk of TMS-related seizures is $<1 \%$ overall. TMS has successfully been used in patients with epilepsy, traumatic brain injuries, and those with a prior TMS-related seizure. The rate of TMS-related seizures is comparable to that of most psychotropic medications. While having a seizure is a rare but serious adverse effect of TMS, the benefits of treating refractory depression with TMS may outweigh the risk of suicidal ideation and other significant complications of depression.
\end{abstract}

Keywords: transcranial magnetic stimulation, transcranial magnetic stimulation-related seizures, transcranial magnetic stimulation safety, transcranial magnetic stimulation in epilepsy patients, head injuries and transcranial magnetic stimulation, transcranial magnetic stimulation in children and adolescents

\section{Introduction}

Transcranial Magnetic Stimulation (TMS) is FDA approved for depression, migraines, and OCD, with other symptoms and disorders being aggressively studied for benefit. Lefaucheur et al $2020^{1}$ have an extensive review of the evidence-based use of rTMS in other disorders such as stroke, multiple sclerosis, tinnitus, anxiety, schizophrenia, substance abuse, Alzheimer's, ALS, epilepsy, panic, PTSD, and others. TMS uses an electromagnetic coil placed on varying areas of the scalp. This coil generates magnetic pulses and stimulates different brain areas to create the desired pathophysiologic and clinical outcome. TMS was first approved for depression in $2008 ;^{2}$ since that time, various coils have been created, altering the area and depth stimulated. It has been suggested that the different coils may have variations 
in side effects and the possible frequency of the adverse event of a seizure. There are also different protocols of stimulation used with TMS, with the most recent advances called theta-burst stimulation and accelerated treatment. Theta-burst stimulation uses three magnetic pulses $20 \mathrm{~ms}$ apart and repeated every $200 \mathrm{~ms}$ of $50 \mathrm{~Hz}$ stimulation. ${ }^{3}$ Accelerated TMS uses multiple TMS stimulation treatments per day. ${ }^{4}$

\section{Methodology}

This paper will focus on the adverse event of a seizure during TMS, which is an abnormal electrical activity and may be due to systemic or local causes. We will also review TMS use in patients with known epilepsy, which is usually due to a structural abnormality of the brain and is that of repeated seizures.

After having a patient who had a seizure during her TMS treatment in 2018, we began looking for all suggestions and references we could find on TMS-related seizures. We had difficulty finding specific information on whether to continue the TMS and what steps to take immediately after the patient had been stabilized from the seizure. From that time forward, we have reviewed articles/books found on PubMed, MEDLINE, Medscape, Cochrane Libray, Scopus, and Google Scholar while collecting information with Mendeley. In this article, we have presented data from 1998 to 2020 (See Table 1). We will discuss the general risk factors associated with seizures, the risks associated with the different TMS coils, reports of seizures with differing TMS protocols, the risk of psychotropic medication alteration on having a seizure, TMS seizures in the child/adolescent population, TMS seizures in bipolar disorder, as well as the possible effects of alcohol use and sleep deprivation on seizures. We will review TMS use with epilepsy and traumatic head injury patients. We will report on continued TMS after a seizure. We will also describe specific steps to take should the patient have a seizure.

\section{TMS and Coils}

The general risks of a seizure with TMS have been reported to be $<1 / 30,000(<0.003 \%)$ by Rossi et al $2009 .{ }^{5}$ The risk of seizure with theta burst is estimated at $0.02 \%$ by Oberman et al 2011. ${ }^{6}$ With the Figure- 8 coil, the risk of seizure has been estimated by Carpenter et al $2012^{7}$ to be $3 / 1000$ or $<1 \%$ overall. Janicak et al $2020^{8}$ reported postmarketing seizure rates with the Neurostar coil are even lower than previously reported. Tendler et al $2018^{9}$ reviewed available data for the Brainsway H1-Coil and reported a seizure rate of $0.087 \%$. They reviewed 31 reported cases of seizures with the H1-Coil and felt most were due to the motor threshold (MT) not being rechecked weekly, as recommended by the company. Six seizures were due to stimulation with intensity $>120 \%$ of the Motor Threshold. No seizures were reported with the first TMS treatment. Nine seizures were associated with medication issues, increased alcohol intake was reported with six patients, and three seizures were associated with sleep issues. While most seizures occur during or around the time of treatment, Cavinato et al $2012^{10}$ reported on a patient with a traumatic brain injury who had a seizure 3 hours after his TMS treatment. Also, Koudijs et al $2010^{11}$ reported an increased frequency of seizures for up to 3 days in four children with known epilepsy who had TMS treatment.

Lerner et al $2019^{12}$ reviewed surveys from 174 providers from 2012 to 2016, revealing 24 seizures out of 318,560 TMS sessions. They reported the risk of seizures with TMS was $0.08 / 1000$ and that "TMS delivered within published guidelines to individuals without risk factors appears to cause fewer than one seizure per 60,000 sessions." In their review, $62 \%$ of seizures occurred on the first exposure to TMS and $75 \%$ within the first three treatments. Of the 24 seizures, seven occurred in patients with congenital epilepsy, all of whom were on anti-epileptic medication at the time. Two patients were described as having refractory epilepsy. Lerner et al described the seizure risk for the different coil types as follows: $0.08 / 1000$ for conventional figure- 8 coils, double cone coils of $0.12 / 1000$ and $0.43 / 1000$ for H-coils. Only three seizures were reported with the $\mathrm{H}$-coil, but only 7577 (2\%) of the 318,560 TMS sessions were completed using the H-coil. The smaller sample size may have made the $\mathrm{H}$-coil numbers appear higher.

\section{TMS Seizure Risk Factors}

Rossi et al $2009^{5}$ conveyed

Seizures are caused by hyper synchronized discharges of groups of neurons in the gray matter, mainly due to an imbalance between inhibitory and excitatory synaptic activity in favor of the latter. Seizures can be induced by rTMS when pulses are applied with relatively highfrequencies and short interval periods between trains of stimulation.

Wasserman $1998^{13}$ stated that "Intervals between series less than 20 seconds were associated with increased seizures". (This may have been the cause of the increased 
Table I Stultz et al TMS Seizure Review Articles

\begin{tabular}{|c|c|c|c|}
\hline & Reference & Coil Type & Description \\
\hline Introduction & $\begin{array}{l}\text { Lefaucheur et al } 2020^{1} \\
\text { McClintock et al } 2018^{2} \\
\text { Chung et al } 2015^{3} \\
\text { Sonmez et al } 2019^{4}\end{array}$ & $\begin{array}{l}\text { Multiple } \\
\text { HI, Figure } 8 \\
\text { Multiple } \\
\text { Not Specified }\end{array}$ & $\begin{array}{l}\text { Review on the use of TMS for multiple disorders using various coil types } \\
\text { such as Figure } 8 \text {, Circular, Double Cone, Hesed } \\
\text { TMS approved for depression in } 2008 \\
\text { Review of the application of theta burst TMS using multiple coil types such } \\
\text { as Double Cone, Figure } 8 \text {, H-coil } \\
\text { Review on the use of accelerated TMS protocol }\end{array}$ \\
\hline TMS and Coils & $\begin{array}{l}\text { Rossi et al } 2009^{5} \\
\text { Oberman et al } 2011^{6} \\
\text { Carpenter et al } 2012^{7} \\
\text { Janicak et al } 2020^{8} \\
\text { Tendler et al } 2018^{9} \\
\text { Cavinato et al } 2012^{10} \\
\text { Koudijis et al } 2010^{11} \\
\text { Lerner et al } 2019^{12}\end{array}$ & $\begin{array}{l}\mathrm{N} / \mathrm{A} \\
\mathrm{N} / \mathrm{A} \\
\text { Figure } 8 \\
\text { Figure } 8 \\
\mathrm{HI} \\
\text { Figure } 8 \\
\text { Round, Fig. } 8 \\
\text { Multiple }\end{array}$ & $\begin{array}{l}\text { General seizure risk with TMS }<0.003 \% \\
\text { Seizure risk with theta burst } r T M S \text { is around } 0.02 \% \\
\text { Seizure risk }<1 \% \text { with TMS } \\
\text { Neurostar seizure rates lower than initially reported } \\
\text { Reviewed } 31 \text { seizure cases, rate of } 0.087 \% \text {. } \\
31 \text { y/o male, } \mathrm{Hx} \text { of severe TBI, had a partial and secondarily generalized } \\
\text { tonic-clonic seizure on } 4 \text { th of } 10 \text { daily sessions } \\
34 \text { children aged } 5 \text { mo. to } 19 \mathrm{y} / 0 \text { with intractable epilepsy underwent TMS, } \\
\text { temporary increase in seizures in } 4 \text { children } \\
\text { Risk of seizures with TMS is } 0.08 / 1000 \text { for Figure } 8,0.12 / 1000 \text { for Double } \\
\text { Cone, } 0.43 \text { for } \mathrm{H} \text {-coil. }\end{array}$ \\
\hline $\begin{array}{l}\text { TMS Seizure Risk } \\
\text { Factors }\end{array}$ & $\begin{array}{l}\text { Rossi et al } 2009^{5} \\
\text { Wasserman } 1998^{13} \\
\text { McClintock et al } 2018^{2} \\
\text { George \& Belmaker } \\
2007^{14}\end{array}$ & $\begin{array}{l}\text { N/A } \\
\text { N/A } \\
\text { HI, Figure } 8 \\
\text { N/A }\end{array}$ & $\begin{array}{l}\text { Higher frequencies and short intervals between trains can increase risk; See } \\
\text { description under TMS \& Coils } \\
<20 \text { second intervals between series leads to increased seizure risk } \\
\text { Tonic-clonic seizure during TMS due to direct stimulation of motor cortex } \\
\text { or adjacent brain areas; Also cited in Intro } \\
\text { Several factors related to increased seizure risk }\end{array}$ \\
\hline Differential Diagnosis & $\begin{array}{l}\text { Sheldon et al } 2002^{15} \\
\text { Kinback } 2018^{16}\end{array}$ & $\begin{array}{l}\mathrm{N} / \mathrm{A} \\
\mathrm{HI}\end{array}$ & $\begin{array}{l}\text { Distinctions between syncope and seizures } \\
42 \text { y/o female, } T \times 2 I \text { had partial tonic seizure }\end{array}$ \\
\hline Theta Burst TMS & $\begin{array}{l}\text { Oberman \& Pascual- } \\
\text { Leone } 2009^{17} \\
\text { Purushotham et al } \\
2018^{18} \\
\text { Lenoir et al } 2018^{19} \\
\text { Allen et al } 2017^{20}\end{array}$ & $\begin{array}{l}\text { Figure } 8 \\
\text { Figure } 8 \\
\text { Double Cone } \\
\text { N/A }\end{array}$ & $\begin{array}{l}33 \text { y/o male, possibly sleep deprived, seizure during final train of session } \\
\text { I5 y/o female, Hx of schizophrenia, Tx I had seizure } \\
2 \text { cases of seizures (One generalized, one partial complex) } \\
\text { Reviewed } 3 \text { TBS studies involving healthy children and pediatric patients } \\
\text { with CNS Disorders, no reported seizures. }\end{array}$ \\
\hline Accelerated TMS & Kallel \& Brunelin 202021 & Figure 8 & $\begin{array}{l}18 \text { y/o female, had seizure that was first localized then generalized during } \\
3 r d \text { session of } 2 \text { nd day }\end{array}$ \\
\hline $\begin{array}{l}\text { TMS and } \\
\text { Psychotropics }\end{array}$ & $\begin{array}{l}\text { Rossi et al } 2009^{5} \\
\text { Loo et al } 2008^{22} \\
\text { Dobek et al } 2015^{23} \\
\text { Lertxurdi et al } 2013^{24} \\
\text { Khoury \& Ghossoub } \\
2019^{25} \\
\text { Thanki et al } 2020^{26}\end{array}$ & $\begin{array}{l}\text { N/A } \\
\text { N/A } \\
\text { N/A } \\
\text { N/A } \\
\text { N/A } \\
\text { Figure } 8\end{array}$ & $\begin{array}{l}\text { Some meds/substances can potentially increase seizure risk; See description } \\
\text { under TMS \& Coils and Risk Factors } \\
\text { If medications are adjusted during TMS, re-check motor threshold } \\
\text { TMS-induced seizures and antidepressant use; Bupropion is not } \\
\text { a contraindication } \\
\text { 2nd gen antipsychotics may have a higher risk of seizures, especially } \\
\text { clozapine } \\
0.5-1.2 \% \text { risk of seizures with antipsychotics, clozapine increases risk the } \\
\text { most } \\
60 \text { y/o male, Hx of hyponatremic seizures, completed TMS safely twice } \\
\text { (once on sertraline, another time on venlafaxine) }\end{array}$ \\
\hline
\end{tabular}


Table I (Continued).

\begin{tabular}{|c|c|c|c|}
\hline & Reference & Coil Type & Description \\
\hline $\begin{array}{l}\text { TMS in Children/ } \\
\text { Adolescents }\end{array}$ & $\begin{array}{l}\text { Allen et al } 2017^{20} \\
\text { Hu et al } 2011^{27} \\
\text { Chiramberro et al } \\
2013^{28} \\
\text { Cullen et al } 2016^{29} \\
\text { Purushotham et al } \\
2018^{18} \\
\text { Wang et al } 2018^{30} \\
\text { Muir et al } 2019^{31} \\
\text { Zewdie et al } 2019^{32}\end{array}$ & $\begin{array}{l}\text { N/A } \\
\text { Figure } 8 \\
\text { Figure } 8 \\
\text { HI } \\
\text { Figure } 8 \\
\text { Figure } 8 \\
\text { HI } \\
\text { Fig. 8, D.Cone }\end{array}$ & $\begin{array}{l}\text { Reviewed } 23 \text { rTMS studies involving children w/CNS disorders \& epilepsy, } 3 \\
\text { seizures in CNS. See Theta Burst TMS } \\
\text { I5 y/o female, on sertraline, generalized tonic-clonic seizure during Tx I, } \\
\text { became hypomanic from TMS } \\
\text { I6 y/o female, Tx I } 2 \text { had seizure, later found high level of blood alcohol } \\
\text { concentration } \\
\text { I7 y/o female, Tx } 8 \text { had generalized tonic-clonic seizure } \\
\text { See description under Theta Burst TMS } \\
16 \text { y/o female, Hx of migraines w/auras, Tx I had generalized tonic-clonic } \\
\text { seizure } \\
\text { Reviewed } 6 \text { pts., I case of seizure in pt. w/Hx of autism, multiple head } \\
\text { injuries, and D/C of oxcarbazepine prior to TMS } \\
\text { Reviewed } 384 \text { children who underwent TMS, no seizures occurred }\end{array}$ \\
\hline $\begin{array}{l}\text { TMS and Bipolar } \\
\text { Disorder }\end{array}$ & $\begin{array}{l}\text { Tharayil et al } 2005^{33} \\
\text { Sakkas et al } 2007^{34} \\
\text { Harel et all } 201 \mathrm{I}^{35} \\
\text { lliceto et al } 2018^{36}\end{array}$ & $\begin{array}{l}\text { Not Specified } \\
\text { Figure } 8 \\
\text { HI } \\
\text { Figure } 8\end{array}$ & $\begin{array}{l}35 \text { y/o pt. with family } \mathrm{Hx} \text { of seizures had generalized seizure while on } \\
\text { lithium and chlorpromazine. } \\
30 \text { y/o female, Type I Bipolar Disorder, manic, stopped diazepam on her } \\
\text { own prior to Tx } 9 \text {, had Jacksonian seizure } \\
\text { I patient out of } 19 \text { had a generalized seizure } \\
37 \text { y/o male, Type I Bipolar Disorder, Hx of TBI, completed TMS safely }\end{array}$ \\
\hline TMS and TBI & $\begin{array}{l}\text { Dhaliwal et al } 2015^{37} \\
\text { Reti et al } 2015^{38} \\
\text { Bernabeu et al } 2004^{39} \\
\text { Cavinato et al } 2012^{10} \\
\text { Pape et al } 2014^{40} \\
\text { Boes et al } 2016^{41} \\
\text { Muir et al } 2019^{31}\end{array}$ & $\begin{array}{l}\text { Fig. 8, Focal } \\
\text { N/A } \\
\text { Circular } \\
\text { Figure } 8 \\
\text { Not Specified } \\
\text { HI } \\
\text { HI }\end{array}$ & $\begin{array}{l}\text { Severe TBI increases seizure risk } \\
\text { TBI increases seizure risk, low frequency rTMS may be better option for } \\
\text { those with a } \mathrm{Hx} \\
28 \text { y/o female with } \mathrm{Hx} \text { of TBI on fluoxetine, had secondarily generalized } \\
\text { tonic-clonic seizure using fast rTMS protocol } \\
\text { See description under TMS \& Coils } \\
2 \text { pts. w/Hx of TBI underwent TMS. Pt. \#I completed safely, Pt. \#2 had an } \\
\text { EEG seizure w/no clinical S/S at Tx } 2 \mathrm{I} \\
27 \text { y/o male had generalized tonic-clonic seizure at Tx I2, Hx of alcohol use } \\
\text { and } 4 \text { head injuries } \\
\text { See description under TMS in Children/Adolescents }\end{array}$ \\
\hline $\begin{array}{l}\text { TMS and Head } \\
\text { Injuries w/o Seizures }\end{array}$ & $\begin{array}{l}\text { Fitzgerald et al } 201 \mathrm{I}^{42} \\
\text { Kreuzer et al } 2013^{43} \\
\text { Neville et al } 2015^{44} \\
\text { Nielson et al } 2015^{45} \\
\text { Englander et al } 2003^{47} \\
\text { Koski et al } 2015^{48} \\
\text { Rutherford et al } 2017^{49} \\
\text { Paxman et al } 2018^{50} \\
\text { Lee \& Kim } 2018^{51} \\
\text { lliceto et al } 2018^{36} \\
\text { Saunders \& Bermudes } \\
2018^{53}\end{array}$ & $\begin{array}{l}\text { Figure } 8 \\
\text { Figure } 8 \\
\text { Figure } 8 \\
\text { Figure } 8 \\
\text { N/A } \\
\text { Figure } 8 \\
\text { Not Specified } \\
\text { Not Specified } \\
\text { Figure } 8 \\
\text { Figure } 8 \\
\text { Figure } 8\end{array}$ & $\begin{array}{l}4 \text { I y/o female with } \mathrm{Hx} \text { of mild TBI, completed } 20 \mathrm{Txs} \\
53 \text { y/o male had severe tinnitus after TBI, completed } 5 \text { Tx series over } 3 \\
\text { years } \\
\text { Double-blind study involving } 36 \text { pts. aged I } 8-60 \text { y/o with Hx of TBI } \\
48 \text { y/o male with } \mathrm{Hx} \text { of severe TBI, finished } 30 \mathrm{Txs} ; 90 \% \text { lower risk of } \\
\text { seizure if none w/in } 2 \text { years of injury } \\
\text { CT scan results and neurosurgical procedures useful in determining risk for } \\
\text { late posttraumatic seizures } \\
\text { Treated I } 2 \text { pts. aged } 20-60 \text { y/o, } 60 \% \text { male, } 60 \% \text { had } \geq 3 \text { concussions } \\
\text { I3 pts. with mild TBI, } 7 \text { real TMS }+6 \text { sham; rTMS may be effective for some } \\
\text { symptoms of post-concussion syndrome } \\
6 I \text { y/o male had chronic dizziness after a mild TBI, completed I0 Txs } \\
\text { I3 pts. aged I9-60 y/o with Hx of TBI, received } 10 \text { sessions of real or sham } \\
\text { TMS } \\
\text { See description under TMS and Bipolar Disorder } \\
55 \text { y/o female had TBI unrelated to TMS after } 10 \text { sessions, resumed TMS II } \\
\text { days later, } 4 \text { different protocols used }\end{array}$ \\
\hline
\end{tabular}

(Continued) 
Table I (Continued).

\begin{tabular}{|c|c|c|c|}
\hline & Reference & Coil Type & Description \\
\hline & $\begin{array}{l}\text { Siddiqi et al } 2018^{54} \\
\text { Stultz et al } 2019^{55}\end{array}$ & $\begin{array}{l}\text { Not Specified } \\
\text { HI }\end{array}$ & $\begin{array}{l}\text { Studied effects of resting-state fMRI-targeted rTMS in a retired NFL player, } \\
\mathrm{Hx} \text { of repetitive head trauma. } \\
23 \mathrm{y} / \mathrm{o} \text { male with } \mathrm{Hx} \text { of } 4 \text { concussions }\end{array}$ \\
\hline TMS and Alcohol Use & $\begin{array}{l}\text { Tendler et al } 2018^{9} \\
\text { Boes et al } 2016^{41} \\
\text { Chiramberro et al } \\
2013^{28}\end{array}$ & $\begin{array}{l}\mathrm{HI} \\
\mathrm{HI} \\
\text { Figure } 8\end{array}$ & $\begin{array}{l}\text { 6/3I pts. reviewed who had a seizure involved increased alcohol intake } \\
\text { See description under TMS and TBI } \\
\text { See description under TMS in Children/Adolescents }\end{array}$ \\
\hline $\begin{array}{l}\text { TMS and Sleep } \\
\text { Deprivation }\end{array}$ & $\begin{array}{l}\text { Nakken et al } 2005^{56} \\
\text { Ferlisi \& Shorvon } 2014^{57} \\
\text { Prikryl \& Kucerova } \\
2005^{58} \\
\text { Tendler et al } 2018^{9} \\
\text { Oberman \& Pascual- } \\
\text { Leone } 2009^{17}\end{array}$ & $\begin{array}{l}\text { N/A } \\
\text { N/A } \\
\text { Not Specified } \\
\text { HI } \\
\text { Figure } 8\end{array}$ & $\begin{array}{l}\text { Reported on } 1677 \text { pts. with epilepsy, those with generalized seizures report } \\
\text { to be more sensitive to sleep deprivation } \\
\text { Pts. with idiopathic generalized epilepsy more sensitive to seizures while } \\
\text { sleep deprived } \\
45 \text { y/o male who was sleep deprived for } 2 \text { nights had a grand mal seizure } \\
\text { during Tx } 6 \\
3 / 3 \text { I pts. reviewed who had a seizure c/o sleep deprivation } \\
\text { See description under Theta Burst TMS }\end{array}$ \\
\hline TMS and Epilepsy & $\begin{array}{l}\text { Bae et al } 2007^{59} \\
\text { Pereira et al } 2016^{60} \\
\text { Vernet et al } 2012^{61} \\
\text { Allen et al } 2017^{20} \\
\text { Koudijis et al } 2010^{11} \\
\text { Stultz et al } 2019^{62} \\
\text { Fitzgerald } 2014^{63}\end{array}$ & $\begin{array}{l}\text { N/A } \\
\text { N/A } \\
\text { Not Specified } \\
\text { N/A } \\
\text { Round, Fig. } 8 \\
\text { HI } \\
\text { Not Specified }\end{array}$ & $\begin{array}{l}\text { Risk of seizures in pts. with epilepsy }<2 \% \\
\text { Reviewed } 410 \text { epilepsy pts. receiving TMS, } 12 \text { of which had a seizure, } \\
\text { suggesting a seizure risk of } 2.9 \% \\
22 \text { y/o male, drug-resistant symptomatic focal epilepsy, had seizure clinically } \\
\text { similar to typical spontaneous seizures } \\
\text { Reviewed } 23 \text { rTMS studies involving children with CNS disorders \& } \\
\text { epilepsy, no seizures reported in epileptic pts. } \\
\text { See description under TMS and Coils } \\
69 \text { y/o female, Hx of complex partial seizures, completed TMS without } \\
\text { having a seizure } \\
57 \text { y/o male, tried ECT in the past, had not experienced seizures for II } \\
\text { years, completed TMS safely at low-frequency }\end{array}$ \\
\hline $\begin{array}{l}\text { Continued TMS After } \\
\text { a Seizure }\end{array}$ & $\begin{array}{l}\text { Bagati et al } 2012^{64} \\
\text { Stultz et al } 2019^{65} \\
\text { Kallel \& Brunelin } 2020^{21}\end{array}$ & $\begin{array}{l}\text { Not Specified } \\
\mathrm{HI} \\
\text { Figure } 8\end{array}$ & $\begin{array}{l}44 \text { y/o male, had seizure during Tx } 4 \text {, continued TMS after being prescribed } \\
\text { valproate } \\
48 \text { y/o female, developed tonic clonic seizure during Tx II, continued TMS } \\
\text { after evaluation with no reported seizures } \\
\text { See description under Accelerated TMS. Continued with TMS after } \\
\text { decreasing to I session per day. }\end{array}$ \\
\hline Treatment Plan & $\begin{array}{l}\text { Fitzgerald \& Daskalakis } \\
2012^{66}\end{array}$ & $\mathrm{~N} / \mathrm{A}$ & $\begin{array}{l}\text { rTMS-related seizures likely to terminate quickly and not require additional } \\
\text { treatment }\end{array}$ \\
\hline
\end{tabular}

seizures reported earlier in the literature using TMS.) McClintock et al $2018^{2}$ stated

the risk of tonic-clonic seizure, a rare event during rTMS, is related to the direct stimulation of motor cortex or stimulation of the adjacent brain areas with spread of neuronal excitation to the motor cortex. Inspection of the contralateral hand for signs of twitching or movement during stimulation may ensure that stimulation does not spread from prefrontal to primary motor cortex, which can lead to generalized seizure induction with tonic-clonic movement pattern.
McClintock also stated, "seizures can occur within safety guidelines, even in patients who present with no known risk factors."

The risk factors associated with TMS-related seizures were discussed in the book entitled "Transcranial Magnetic Stimulation in Neuropsychiatry" (George and Belmaker $2007^{14}$ ). They reported on the increased risk of seizures with focal or generalized encephalopathy, severe head trauma, non-treated epilepsy, family history of epilepsy in first-degree relatives, heavy alcohol use, severe 
cardiac disease, increased intracranial pressure, medications that lower seizure threshold, cocaine usage, and other epileptogenic drugs. Other risk factors associated with seizures described throughout the years include a personal history of seizure, stroke, epilepsy, concussions, family history of brain tumors, eating disorders, neurologic disease with altered seizure threshold, sleep deprivation, excessive caffeine/stimulant/cocaine use, MDMA (Ecstasy) use, theophylline use, alcohol withdrawal, benzodiazepine withdrawal, electrolyte disturbance (decreased sodium, change in glucose), other medications that lower seizure threshold, depression, demyelinating disorders (such as Multiple Sclerosis), and fever.

\section{Differential Diagnosis of TMS Seizures}

Concerning the differential diagnosis, a distinction must be made between vasovagal syncope and seizure during an episode. Vasovagal syncope symptoms include a transient rapid onset, self-limited loss of consciousness associated with lightheadedness, pale skin, yawning, blurred vision, and a feeling of being warm, cold, clammy, or sweaty (Sheldon et al $2002^{15}$ ). Jerky myoclonic movements have also been reported with both vasovagal syncope and seizures.

TMS seizures can be generalized or partial. Kinback in $2018^{16}$ described a partial tonic seizure in a 42-year-old white female using the H1 coil during treatment 21, where she developed tense jaw and arm muscles, fixed gaze, unresponsiveness, and bilateral upper extremity flexion with clinched wrists. She had slight spine arching but no lower extremity involvement. She stayed fully aware without incontinence or LOC.

\section{Theta-Burst TMS and Seizures}

As previously stated, theta-burst TMS has been associated with an estimated seizure risk of $0.02 \%{ }^{6}$ Oberman and Pascual-Leone $2009^{17}$ recounted a seizure in a 33-year-old man with no risk factors (except possible sleep deprivation) using theta burst. Purushotham et al $2018^{18}$ reported on a 15-year-old female with schizophrenia who developed a seizure with theta burst within the first 30 seconds of the first session. Lenoir et al $2018^{19}$ described two cases of seizures with theta burst. One had a generalized seizure, and one a partial complex seizure. Allen et al $2017^{20}$ identified no seizures after reviewing three theta-burst studies in 90 healthy children and 40 pediatric patients with CNS disorders.

\section{Accelerated TMS and Seizures}

Kallel and Brunelin 2020 ${ }^{21}$ described an 18-year-old female with major depression receiving a protocol of 5 sessions per day during four consecutive working days over the left dorsolateral prefrontal cortex using the MagPro X30 figure-eight coil. The patient developed a seizure on the third session of the second day. The seizure underwent secondary generalization and was associated with urinary incontinence and postictal confusion. Twelve days later, the patient agreed to additional TMS given at $1-\mathrm{Hz}$ right DLPFC treatment with one session per day for 30 additional sessions. She also had maintenance TMS scheduled every 2 weeks afterwards and had no seizure activity during her continued or maintenance treatments.

\section{TMS, Psychotropic Medications, and Seizures}

Over the years, various medications have been used during which a TMS-related seizure has occurred, but we have found no absolute contraindication with any specific medication to date. Rossi et $\mathrm{al}^{5}$ in their safety article of 2009 listed several medications described as having either a strong potential for hazard or a relative hazard for interactions with TMS. They also included medications that if withdrawn could create a strong relative hazard. (Please see their article for a complete list of medications listed.) Since their 2009 article, many of these substances have been used during TMS without incident.

There has been discussion about changing medications during the TMS treatment, and Loo et al $2008^{22}$ stated,

If medications are altered during the TMS course, the motor threshold should be re-measured and the stimulus intensity adjusted accordingly. This is based on the premise that medications which alter seizure threshold could also alter motor cortical threshold.

Dobek et al $2015^{23}$ while studying bupropion treatment with TMS and after an extensive literature review reported the following seizure incidence rates in percent for psychotropic medications independent of TMS use: Bupropion SR 0.1\%, Bupropion IR 0.4\%, Citalopram $0.25 \%$, Duloxetine $0.2 \%$, Fluoxetine $0.2 \%$, Fluvoxamine $0.2 \%$, Mirtazapine $0.04 \%$, Paroxetine $0.1 \%$, Sertraline up to $0.2 \%$, Venlafaxine $0.3 \%$, Tricyclics $0.1-0.4 \%$, Olanzapine $0.9 \%$, Quetiapine $0.8 \%$, Aripiprazole $0.4 \%$, Ziprasidone $0.4 \%$, and Risperidone $0.3 \%$. Lertxurdi et al 
$2013^{24}$ reported that second-generation antipsychotics might have a higher risk of seizures, especially clozapine and possibly olanzapine and quetiapine. Khoury and Ghossoub $2019^{25}$ revealed studies with antipsychotics are associated with $0.5 \%$ to $1.2 \%$ risk of seizures, and also reported clozapine appears to increase the risk the most. The above information reveals that the rates of seizures for psychotropic medications are similar or higher than the general TMS rates of $<0.003 \%$ to $0.087 \%$ mentioned previously. Dobek et $\mathrm{al}^{23}$ also stated that TMS-induced seizure data are not associated with any particular antidepressant, and bupropion is not a contraindication to TMS. Thanki et al $2020^{26}$ even reported on using rTMS in a 60 -year-old male with a history of hyponatremic seizures with antidepressants on two different occasions while on sertraline $50 \mathrm{mg}$ and then later on venlafaxine $75 \mathrm{mg}$, who was later successfully treated with $1 \mathrm{~Hz}$ TMS to the right dorsolateral prefrontal cortex at $90 \%$ of the resting motor threshold without having a seizure.

\section{TMS Seizures in Child/Adolescent Patients}

The overall risk of TMS-related seizures in the child/ adolescent population appears to be similar to that of the adult. Allen et al $2017^{20}$ reported on a review in the pediatric population of 23 repetitive TMS (rTMS) studies (including $230 \mathrm{CNS}$ and 24 epileptic children) identifying three seizures in the CNS patients, with a risk of $0.14 \%$ per session. They reviewed three theta-burst studies in 90 healthy children and 40 pediatric patients with CNS disorders and identified no seizures.

Case reports of seizures in the child/adolescent patient have been reported. Hu et al $2011^{27}$ described an adolescent female on Zoloft who had a seizure and became hypomanic with TMS. She subsequently stopped TMS. Chiramberro et al $2013^{28}$ reported on a 16-year-old girl who had a seizure during the 12th treatment session with TMS. Of interest, the patient was on sertraline, olanzapine, and hydroxyzine, and she was also found to have used alcohol around the time of treatment. Cullen et al $2016^{29}$ recounted a 17-year-old female in a sham-controlled study who developed a generalized tonic-clonic seizure during the 8th treatment session of TMS (which was the first day at $120 \%$ MT). Purushotham et al $2018^{18}$ reported a 15 year-old girl with schizophrenia who had a seizure while using theta-burst TMS. Wang et al $2018^{30}$ told of a 16-year -old girl previously diagnosed as having migraine with aura who had a seizure 10 seconds after the onset of the third rTMS train.

In the transition years to adulthood ages (18-20), Muir et al $2019^{31}$ reviewed six patients and presented a case of one seizure using the $\mathrm{H} 1$ coil at $120 \%$ MT with the risk factors of autism, multiple head injuries, and the discontinuation of oxcarbazepine during the week before TMS initiation. They felt the spontaneous discontinuation of oxcarbazepine was the most likely cause. Most recently, Zewdie et al $2019^{32}$ reviewed the results of 384 children over ten years that underwent TMS or direct current stimulation (tDCS). Neuromodulation TMS occurred in 119 of the patients with a median age of 14. "Despite 221 $(58 \%)$ of the patients having some sort of brain injury/or epilepsy, no seizures occurred with single, paired, or rTMS or with tCDS."

\section{TMS Seizures in Bipolar Patients}

TMS seizures have been described in diagnoses other than depression and in the bipolar patient have been reported in 2005 by Tharayil et al, by Sakkas et al, and described again by Harel et al in 2011 . Tharayil et al $2005^{33}$ reported a generalized seizure in a bipolar patient while on chlorpromazine and lithium who also had a positive family history of seizures. Sakkas et al $2007^{34}$ described a Jacksonian seizure in a manic patient treated with rTMS. Harel et al $2011^{35}$ studied TMS in 19 Bipolar patients and had only one generalized seizure patient. In 2018 , Iliceto et $\mathrm{al}^{36}$ treated a patient with bipolar disorder, generalized anxiety, a TBI, and a history of a suicide gesture without the patient having a seizure. The specific seizure rate with TMS in bipolar disorder is not clear at this time.

\section{TMS in Traumatic Brain Injury Patients}

Head injuries are another situation associated with an increased risk of seizures. Dhaliwal et al $2015^{37}$ stated, "patients with severe TBI do show an increased risk of unprovoked seizures," and

there is a strong connection between the severity of a brain injury and the subsequent risk of seizures; individuals with mild to moderate TBI have a substantially lower seizure risk than those with severe TBI.

Reti et al $2015^{38}$ indicated,

TBI is associated with an increased risk of both early and late spontaneous seizures, a significant consideration in 
evaluating rTMS as a potential treatment for TBI depression. Whilst the risk from rTMS is low; underlying neuropathology may somewhat increase that risk.

They suggested that low-frequency rTMS might be less likely to trigger a seizure.

Various reports of patients with a history of a head injury having a TMS-related seizure have been described. Bernabeu et al $2004^{39}$ reported a seizure in a TBI patient on fluoxetine but was using a brief interstimulus interval. Cavinato et al $2012^{10}$ described a 31year-old male with a history of a severe TBI 8 months before TMS initiation. He had a secondary generalized seizure on the 4 th of 10 daily sessions. TMS was delivered at 90\% MT, $20 \mathrm{~Hz}$, 1s train duration, and 1-minute inter-train interval to the dorsolateral prefrontal cortex (DLPFC). The seizure developed 3 hours after treatment. Pape et al $2014^{40}$ reported on a 32-year-old male who had a TBI 9 years before TMS initiation who had an EEG identified seizure during the treatment with no clinical expression. Boes et al $2016^{41}$ reported on a 27year-old male with MDE, GAD, alcohol use, and a history of 4 prior head injuries. He was also sleep deprived. He developed a seizure during the 12th treatment session. As described previously, Muir et al $2019^{29}$ presented a patient with a history of oxcarbazepine withdrawal the week before, autism, and multiple head injuries who had a seizure.

\section{TMS Treatment Without Seizures in Patients with Head Injuries}

Transcranial Magnetic Stimulation has also been used successfully without seizures in patients with a history of brain injury. Fitzgerald et al $2011^{42}$ presented one of the original studies about using TMS without adverse events in a depressed patient with a history of a mild TBI 14 years before the TMS. Kreuzer et al $2013^{43}$ treated a TBI patient with TMS for severe tinnitus after a head injury with five treatment series of $1 \mathrm{~Hz}$ to the left primary auditory cortex at $110 \%$ MT and no reported seizure. Neville et al $2015^{44}$ completed a randomized controlled trial of 36 patients with TBI divided into two groups and administered ten sessions of $10 \mathrm{~Hz}$ TMS over the left DLPFC, which demonstrated improvement in depression and cognitive functioning. Nielson et al $2015^{45}$ reported on a 48 -year-old man with a severe TBI history 5 years before TMS was administered with lowfrequency right dorsolateral prefrontal cortex stimulation daily for 6 weeks. The patient demonstrated a $49 \%$ improvement in his Hamilton Depression Rating Scale ${ }^{46}$ with treatment. In their article, they set forth that those who have not had a seizure within 2 years of injury have a $90 \%$ lower risk of seizure based on work by Englander et al $2003 .^{47}$

Koski et al $2015^{48}$ treated 12 patients with postconcussive symptoms (headaches, depression, and cognitive deficits) following mild TBI using rTMS to the left DLPFC at 5-sec trains, $10 \mathrm{~Hz}$, and $110 \%$ Motor Threshold. Their patients demonstrated a decrease of 14.6 points $(p=$ 0.009 ) of post-concussive symptoms. Rutherford et al $2017^{49}$ studied 13 patients with mild TBI delivering 13 treatment sessions of rTMS to the left DLPFC at $20 \mathrm{~Hz}$ in 1.5-second trains of 30 pulses and an inter-stimulation separation of 28.5 seconds. Paxman et al $2018^{50}$ safely used TMS in a mild TBI patient when treating for chronic dizziness with ten sessions of rTMS to the left DLPFC at $70 \%$ motor threshold and a frequency of $10 \mathrm{HZ}$. Lee and Kim $2018^{51}$ studied 13 patients divided into an experimental group and sham group. The patients were given rTMS to the right DLPFC for ten sessions and demonstrated improvements in mood based on the MontgomeryAsberg Depression Rating Scale. ${ }^{52}$ Iliceto et al $2018^{36}$ treated a 37-year-old man with a severe TBI secondary to a suicide attempt who had a history of anxiety and bipolar disorder. The patient received 30 treatments of 6 $\mathrm{Hz}$ TMS to the left DLPFC at $120 \%$ MT and a 26 -second inter-stimulation interval. Using the PHQ-9 he had a $70.8 \%$ improvement in mood.

Saunders and Bermudes $2018^{53}$ described a 55-year female with a TBI with loss of consciousness during her series of TMS treatments. The event was unrelated to the TMS, and the patient was hospitalized for 4 days. TMS was restarted 11 days after the injury without incident. In 2018 Siddiqi et $\mathrm{al}^{54}$ used 20 sessions of bilateral TMS in a retired NFL defensive lineman. The patient reported at least 12 previous concussions. Using the Montgomery Asberg Depression Rating Scale, the patient documented improved scores from 32 to 9 . Stultz et al $2019^{55}$ presented a case of a 23-year-old male with a history of four concussions (two of which required hospitalization) having significant depression, generalized anxiety, panic, and OCD symptoms who received 34 TMS treatments and nine booster sessions without a seizure and with improvement in mood and anxiety. He was treated with the $\mathrm{H} 1$ coil at $120 \%$ MT to the left DLPFC. 


\section{TMS Seizures and Alcohol}

Excessive alcohol use and withdrawal can precipitate seizures and has been found to possibly increase the risk of TMS-related seizures. Tendler et al $2018^{9}$ indicated 6 of the 31 patients reviewed with TMS-related seizures using the H1 coil had a history of increased alcohol intake. Alcohol use was also reported in TMS seizure patients' history by Boes et al $2016^{41}$ and Chiramberro et al 2013. ${ }^{28}$ These cases are described elsewhere in this report.

\section{TMS Seizures and Sleep Deprivation}

Sleep deprivation has long been identified as a precipitant to having a seizure in epilepsy patients and may increase the risk of a TMS-related seizure. Nakken et al $2005^{56}$ reported on 1677 patients with epilepsy revealing 53\% reported at least one seizure precipitant, with $30 \%$ reporting two or more factors had contributed at times to having a seizure. The three most common seizure-precipitating factors were emotional stress, sleep deprivation, and tiredness. Patients having generalized seizures were reported to be more sensitive to sleep deprivation. Ferlisi and Shorvon $2014^{57}$ studied 104 patients at a tertiary-care adult epilepsy clinic to identify triggering factors to their epilepsy. Ninety-seven percent cited at least one precipitant, with stress, sleep deprivation, and fatigue being the most commonly reported. Those with idiopathic generalized epilepsy were more sensitive to seizures during wake periods and sleep deprivation, with those having extratemporal epilepsy reporting more seizures during sleep.

There are reports of patients having a seizure during TMS in which sleep deprivation may have played a role. Prikryl and Kucerova $2005^{58}$ described a seizure in a sleep-deprived depressed patient at $110 \% \mathrm{MT}, 15 \mathrm{~Hz}$, and train duration of 10 seconds. Tendler et al $2018^{9}$ reported that of the 31 patients they reviewed having had a seizure with the $\mathrm{H} 1$ coil; three had sleep issues. Oberman and Pascual-Leon $2009^{17}$ reported on a 33-year-old male who had flown from London to Boston and may have been sleep-deprived before the TMS in which he had a seizure.

\section{TMS in Patients with Epilepsy}

TMS has been used in patients with known epilepsy. Bae et al $2007^{59}$ reported the seizure risk with TMS in patients with epilepsy is less than $2 \%$ ( 4 of 280 patients). Pereira et al $2016^{60}$ recounted $12 / 410$ patients who had a history of epilepsy developed a seizure during TMS, suggesting a crude rate of seizures per subject of $2.9 \%$ in epilepsy patients treated with TMS. Vernet et al $2012^{61}$ usually indicated TMS-associated seizures in epilepsy patients have been clinically similar to the patients' typical spontaneous seizures, and the risk of a seizure in temporal association with TMS is less than $2 \%$ in epilepsy patients. Allen et al $2017,{ }^{20}$ in their previously mentioned review of 23 rTMS studies using TMS in children, included 24 pediatric patients with epilepsy. Koudijs et al $2010^{11}$ reported an increased frequency of seizures for up to 3 days after TMS in 4 children with known epilepsy based upon follow-up phone conversations. Stultz et al $2019^{62}$ reported on a 69 -year-old white female with a history of complex partial seizures, resistant depression, generalized anxiety disorder, and panic disorder who had three generalized seizures in her lifetime. She received 31 TMS treatments with the H1 coil at $120 \%$ MT over the left DLPFC without having a seizure. She has returned for booster TMS sessions without having a seizure. Fitzgerald $2014^{63}$ described a 57 -year-old man diagnosed with epilepsy when he was 26 years old who had been stabilized on sodium valproate and lamotrigine. $\mathrm{He}$ was later treated with rTMS of $1 \mathrm{~Hz}$ stimulation to the right dorsolateral prefrontal cortex for 20 consecutive weekdays with documented improvement in both mood and anxiety without a seizure.

\section{Continued TMS After a Seizure}

If the patient does have a seizure, then the question is that of whether to continue treatment. Bagati et al $2012^{64}$ described a patient who developed a seizure during treatment session \#4, and while using valproate to cover for seizures, he finished TMS. Stultz $2019^{65}$ reported previously on a patient who had a seizure during treatment session \#11 but was then able to continue TMS without additional seizures or additional medications. The patient received 39 treatment sessions in total. In the accelerated TMS article referenced previously by Kalle and Brunelin $^{21}$, the patient continued treatment and later maintenance treatment after having a seizure.

\section{The Treatment Plan Should a Patient Have a Seizure}

Fitzgerald and Daskalakis ${ }^{66}$ report,

Seizures are likely to terminate fairly rapidly and not require medication treatment: emergency response medical units should potentially be summoned if the seizure does not terminate in several minutes. 
Most treatment recommendations for TMS seizures are supportive, with ensuring patient safety, avoiding aspiration, and monitoring blood pressure if possible. Currently, there are no specific recommendations for oxygen or suctioning during the seizure.

As seizures are usually a rare occurrence in the outpatient psychiatric office, one must also debrief the staff and may use the episode as a teachable moment to review seizure protocols with the staff and emphasize the need to be discussing sleep hygiene continually, alcohol use, medication change, etc., with patients daily before their TMS treatment. Concerning documentation, always include the date of occurrence, TMS treatment number, train, placement, motor threshold, and device used. A detailed description of the seizure, how it first presented and then progressed should be described. Documentation should include any identifiable risk factors and the absence of others. List all medications the patient was taking at the time of the seizure, including non-psychotropic meds. Review with the patient any changes they may have had before the seizure concerning sleep, medications, or alcohol/caffeine use. The risk of not treating severe depression versus the risk of another seizure must be discussed with the patient and the family if TMS is to be continued. While not always necessary, some practitioners have added antiepileptic medications to the treatment regimen before continuing TMS treatment. The seizure should be reported to the FDA and the manufacturer of the TMS unit. Also, one should consider a letter to the editor of a journal to help keep others informed of potential risks and outcomes.

\section{Conclusion}

In summary, while TMS has a risk of seizure that is generally $<1 \%$ overall, some situations may increase that risk, such as alcohol use, brain injury, sleep deprivation, family history, etc. Various case studies have been described in this article in which these situations may have been contributing factors. Traditional TMS, theta burst, accelerated TMS, and child/adolescent TMS use have been reviewed with similar risks for seizures. Comparable seizure rates are reported with both TMS and various psychotropic medications we prescribe daily. (TMS has a lower risk than some of the medications.) We have described successful continued TMS use in patients having had a seizure during TMS and in those with a history of head injury/concussion. TMS use in patients with known epilepsy has also been reviewed. While seizure is a potentially serious adverse event of TMS and must be discussed with the patient, the benefit of treating refractory depression and possibly suicidal ideation may outweigh the risk.

\section{Disclosure}

The authors have no conflict of interests to report.

\section{References}

1. Lefaucheur JP, Aleman A, Baeken C, et al. Evidence-based guidelines on the therapeutic use of repetitive transcranial magnetic stimulation (rTMS): an update (2014-2018). Clin Neurophysiol. 2020;131 (2):474-528. doi:10.1016/j.clinph.2019.11.002

2. McClintock SM, Reti IM, Carpenter LL, et al. Consensus recommendations for the clinical application of repetitive transcranial magnetic stimulation (rTMS) in the treatment of depression. J Clin Psychiatry. 2018;79(1):35-48. doi:10.4088/JCP.16cs10905

3. Chung SW, Hoy KE, Fitzgerald PB. Theta-burst stimulation: a new form of TMS treatment for depression? Depress Anxiety. 2015;32 (3):182-192. doi:10.1002/da.22335

4. Sonmez AI, Camsari DD, Nandakumar AL, et al. Accelerated TMS for depression: a systematic review and meta-analysis. Psychiatry Res. 2019;273:770-781. doi:10.1016/j.psychres.2018.12.041

5. Rossi S, Hallett M, Rossini PM, et al. Safety, ethical considerations, and application guidelines for the use of transcranial magnetic stimulation in clinical practice and research. Clin Neurophysiol. 2009;120 (12):2008-2039. doi:10.1016/j.clinph.2009.08.016

6. Oberman L, Edwards D, Eldaief M, Pascual-Leone A. Safety of theta burst transcranial magnetic stimulation: a systematic review of the literature. J Clin Neurophysiol. 2011;28(1):67-74. doi:10.1097/WNP. 0b013e318205135f

7. Carpenter LL, Janicak PG, Aaronson ST, et al. Transcranial magnetic stimulation (TMS) for major depression: a multisite, naturalistic, observational study of acute treatment outcomes in clinical practice. Depress Anxiety. 2012;29(7):587-596. doi:10.1002/da.21969

8. Janicak P, Heart K, McGugan B. 166 Post market rate of seizures during TMS treatment with NeuroStar ${ }^{\circledR}$ system appears to be lower than previously estimated. CNS Spectr. 2020;25(2):306. doi:10.1017/ S1092852920000826

9. Tendler A, Roth Y, Zangen A. Rate of inadvertently induced seizures with deep repetitive transcranial magnetic stimulation. Brain Stimul. 2018;11(6):1410-1414. doi:10.1016/j.brs.2018.09.001

10. Cavinato M, Iaia V, Piccione F. Repeated sessions of sub-threshold 20-Hz rTMS. Potential cumulative effects in a brain-injured patient. Clin Neurophysiol. 2012;123(9):1893-1895. doi:10.1016/j.clinph. 2012.02.066

11. Koudijs SM, Leijten FSS, Ramsey NF, van Nieuwenhuizen O, Braun KPJ. Lateralization of motor innervation in children with intractable focal epilepsy-a TMS and fMRI study. Epilepsy Res. 2010;90(1-2):140-150. doi:10.1016/j.eplepsyres.2010.04.004

12. Lerner AJ, Wassermann EM, Tamir DI. Seizures from transcranial magnetic stimulation 2012-2016: results of a survey of active laboratories and clinics. Clin Neurophysiol. 2019;130(8):1409-1416. doi:10.1016/j.clinph.2019.03.016

13. Wassermann EM. Risk and safety of repetitive transcranial magnetic stimulation: report and suggested guidelines from the international workshop on the safety of repetitive transcranial magnetic stimulation, June 5-7, 1996. Electroencephalogr Clin Neurophysiol. 1998;108(1):1-16. doi:10.1016/S0168-5597(97)00096-8

14. George MS, Belmaker RH, eds. Transcranial Magnetic Stimulation in Clinical Psychiatry. Washington, D.C: American Psychiatric Publishing; 2007. 
15. Sheldon R, Rose S, Ritchie D, et al. Historical criteria that distinguish syncope from seizures. J Am Coll Cardiol. 2002;40(1):142-148. doi:10.1016/S0735-1097(02)01940-X

16. Kinback KM. Unusual or possibly dangerous TMS side effects, a case series. Brain Stimul. 2018;11(3):e4. doi:10.1016/j.brs.2018.01.017

17. Oberman LM, Pascual-Leone A. Report of seizure induced by continuous theta burst stimulation. Brain Stimul. 2009;2(4):246-247. doi:10.1016/j.brs.2009.03.003

18. Purushotham A, Sinha VK, Goyal N, Tikka SK. Intermittent theta burst stimulation induced seizure in a child with schizophrenia: a case report. Brain Stimul. 2018;11(6):1415-1416. doi:10.1016/j.brs.2018. 09.008

19. Lenoir C, Algoet M, Vanderclausen C, Peeters A, Santos SF, Mouraux A. Report of one confirmed generalized seizure and one suspected partial seizure induced by deep continuous theta burst stimulation of the right operculo-insular cortex. Brain Stimul. 2018;11(5):1187-1188. doi:10.1016/j.brs.2018.05.004

20. Allen CH, Kluger BM, Buard I. Safety of transcranial magnetic stimulation in children: a systematic review of the literature. Pediatr Neurol. 2017;68:3-17. doi:10.1016/j.pediatrneurol.2016.12.009

21. Kallel L, Brunelin J. A case report of transcranial magnetic stimulation-related seizure in a young patient with major depressive disorder receiving accelerated transcranial magnetic stimulation. $J E C T$. 2020;36(3):e31-e32. doi:10.1097/YCT.0000000000000666

22. Loo CK, McFarquhar TF, Mitchell PB. A review of the safety of repetitive transcranial magnetic stimulation as a clinical treatment for depression. Int J Neuropsychopharmacol. 2008;11(1):131-147. doi: $10.1017 /$ S1461145707007717

23. Dobek CE, Blumberger DM, Downar J, Daskalakis ZJ, VilaRodriguez F. Risk of seizures in transcranial magnetic stimulation: a clinical review to inform consent process focused on bupropion. Neuropsychiatr Dis Treat. 2015;11:2975. doi:10. 2147/NDT.S91126

24. Lertxundi U, Hernandez R, Medrano J, Domingo-Echaburu S, García M, Aguirre C. Antipsychotics and seizures: higher risk with atypicals? Seizure. 2013;22(2):141-143. doi:10.1016/j.seizure.2012.10.009

25. Khoury R, Ghossoub E. Antipsychotics and seizures: what are the risks? Curr Psychiatr. 2019;18(3):21-22.:.

26. Thanki MV, Baliga SP, Parameshwaran S, Rao NP, Mehta UM, Thirthalli J. Safe administration of low frequency rTMS in a patient with depression with recurrent antidepressant-associated hyponatremic seizures. Brain Stimul. 2020;13(5):1168-1169. doi:10.1016/j. brs.2020.06.001

27. Hu S-H, Wang -S-S, Zhang -M-M, et al. Repetitive transcranial magnetic stimulation-induced seizure of a patient with adolescent-onset depression: a case report and literature review. J Int Med Res. 2011;39 (5):2039-2044. doi:10.1177/147323001103900552

28. Chiramberro M, Lindberg N, Isometsä E, Kähkönen S, Appelberg B. Repetitive transcranial magnetic stimulation induced seizures in an adolescent patient with major depression: a case report. Brain Stimul. 2013;6(5):830-831. doi:10.1016/j.brs.2013.02.003

29. Cullen KR, Jasberg S, Nelson B, Klimes-Dougan B, Lim KO, Croarkin PE. Seizure induced by deep transcranial magnetic stimulation in an adolescent with depression. $J$ Child Adolesc Psychopharmacol. 2016;26(7):637-641. doi:10.1089/cap.2016.0070

30. Wang T, Huang L, Xu H, et al. Seizure induced by repetitive transcranial magnetic stimulation in an adolescent with migraine with aura. Brain Stimul. 2018;11(6):1380-1381. doi:10.1016/j.brs.2018.07.052

31. Muir O, MacMillan C, Khan M, Sang L, Aron T. Safety and tolerability of dTMS treatment in 18-20 year old patients: case series. Brain Stimul. 2019;12(4):e137-e138. doi:10.1016/j. brs.2019.03.049

32. Zewdie E, Ciechanski P, Kuo HC, et al. Safety and tolerability of transcranial magnetic and direct current stimulation in children: prospective single center evidence from 3.5 million stimulations. Brain Stimul. 2020;13(3):565-575. doi:10.1016/j.brs.2019.12.025
33. Tharayil BS, Gangadhar BN, Thirthalli J, Anand L. Seizure with single-pulse transcranial magnetic stimulation in a 35-year-old otherwise-healthy patient with bipolar disorder. $J$ ECT. 2005;21 (3):188-189. doi:10.1097/01.yct.0000177516.38421.9c

34. Sakkas P, Theleritis CG, Psarros C, Papadimitriou GN, Soldatos CR. Jacksonian seizure in a manic patient treated with rTMS. World J Biol Psychiatry. 2008;9(2):159-160. doi:10.1080/15622970701624595

35. Harel EV, Zangen A, Roth Y, Reti I, Braw Y, Levkovitz Y. H-coil repetitive transcranial magnetic stimulation for the treatment of bipolar depression: an add-on, safety and feasibility study. World J Biol Psychiatry. 2011;12(2):119-126. doi:10.3109/15622975.2010.510893

36. Iliceto A, Seiler RL, Sarkar K. Repetitive transcranial magnetic stimulation for treatment of depression in a patient with severe traumatic brain injury. Ochsner J. 2018;18(3):264-267. doi:10.31486/toj.17.0075

37. Dhaliwal SK, Meek BP, Modirrousta MM. Non-invasive brain stimulation for the treatment of symptoms following traumatic brain injury. Front Psychiatry. 2015;6. doi:10.3389/fpsyt.2015.00119.

38. Reti IM, Schwarz N, Bower A, Tibbs M, Rao V. Transcranial magnetic stimulation: a potential new treatment for depression associated with traumatic brain injury. Brain Inj. 2015;29(7-8):789-797. doi:10.3109/02699052.2015.1009168

39. Bernabeu M, Orient F, Tormos JM, Pascual-Leone A. Seizure induced by fast repetitive transcranial magnetic stimulation. Clin Neurophysiol. 2004;115(7):1714-1715. doi:10.1016/j.clinph.2004. 02.021

40. Pape TL-B, Rosenow JM, Patil V, et al. rTMS safety for two subjects with disordered consciousness after traumatic brain injury. Brain Stimul. 2014;7(4):620-622. doi:10.1016/j.brs.2014.03.007

41. Boes AD, Stern AP, Bernstein M, et al. H-coil repetitive transcranial magnetic stimulation induced seizure in an adult with major depression: a case report. Brain Stimul. 2016;9(4):632-633. doi:10.1016/j. brs.2016.04.013

42. Fitzgerald PB, Hoy KE, Maller JJ, et al. Transcranial magnetic stimulation for depression after a traumatic brain injury. $J E C T$. 2011;27(1):38-40. doi:10.1097/YCT.0b013e3181eb30c6

43. Kreuzer PM, Landgrebe M, Frank E, Langguth B. Repetitive transcranial magnetic stimulation for the treatment of chronic tinnitus after traumatic brain injury. J Head Trauma Rehabil. 2013;28 (5):386-389. doi:10.1097/HTR.0b013e318254736e

44. Neville IS, Hayashi CY, El Hajj SA, et al. Repetitive transcranial magnetic stimulation (rTMS) for the cognitive rehabilitation of traumatic brain injury (TBI) victims: study protocol for a randomized controlled trial. Trials. 2015;16(1):440. doi:10.1186/s13063-0150944-2

45. Nielson DM, McKnight CA, Patel RN, Kalnin AJ, Mysiw WJ. Preliminary guidelines for safe and effective use of repetitive transcranial magnetic stimulation in moderate to severe traumatic brain injury. Arch Phys Med Rehabil. 2015;96(4):S138-S144. doi:10.1016/ j.apmr.2014.09.010

46. Hamilton M. A rating scale for depression. J Neurol Neurosurg Psychiatry. 1960;23(1):56-62. doi:10.1136/jnnp.23.1.56

47. Englander J, Bushnik T, Duong TT, et al. Analyzing risk factors for late posttraumatic seizures: a prospective, multicenter investigation. Arch Phys Med Rehabil. 2003;84(3):365-373. doi:10.1053/ apmr.2003.50022

48. Koski L, Kolivakis T, Yu C, Chen J-K, Delaney S, Ptito A. Noninvasive brain stimulation for persistent postconcussion symptoms in mild traumatic brain injury. $J$ Neurotrauma. 2015;32 (1):38-44. doi:10.1089/neu.2014.3449

49. Rutherford G, Mansouri B, Zhang W, et al. rTMS as a treatment for mild traumatic brain injury. Brain Stimul. 2017;10(2):481. doi:10.1016/j.brs.2017.01.409

50. Paxman E, Stilling J, Mercier L, Debert CT. Repetitive transcranial magnetic stimulation (rTMS) as a treatment for chronic dizziness following mild traumatic brain injury. BMJ Case Rep. 2018; bcr-2018-226698. doi:10.1136/bcr-2018-226698 
51. Lee SA, Kim M-K. Effect of low frequency repetitive transcranial magnetic stimulation on depression and cognition of patients with traumatic brain injury: a randomized controlled trial. Med Sci Monit. 2018;24:8789-8794. doi:10.12659/MSM.911385

52. Montgomery SA, Asberg M. A new depression scale designed to be sensitive to change. $B r J$ Psychiatry. 1979;134(4):82-89. doi:10. 1192/bjp.134.4.382

53. Saunders R, Bermudes R. TBI during a course of TMS - a case report. Brain Stimul. 2018;11(3):e6. doi:10.1016/j.brs.2018.01. 021

54. Siddiqi SH, Trapp NT, Laumann TO, et al. Efficacy and neural network changes with fMRI-targeted rTMS for neuropsychiatric sequelae of repetitive head trauma in a retired NFL player. Brain Stimul. 2018;11(3):e7. doi:10.1016/j.brs.2018.01.023

55. Stultz DJ, Voltin R, Thistlethwaite D, et al. Transcranial magnetic stimulation in the treatment of post-concussion depression. Brain Stimul. 2019;12(4):e140. doi:10.1016/j.brs.2019.03.057

56. Nakken KO, Solaas MH, Kjeldsen MJ, Friis ML, Pellock JM, Corey LA. Which seizure-precipitating factors do patients with epilepsy most frequently report? Epilepsy Behav. 2005;6(1):85-89. doi:10.1016/ j.yebeh.2004.11.003

57. Ferlisi M, Shorvon S. Seizure precipitants (triggering factors) in patients with epilepsy. Epilepsy Behav. 2014;33:101-105. doi:10. 1016/j.yebeh.2014.02.019

58. Prikryl R, Kucerova H. Occurrence of epileptic paroxysm during repetitive transcranial magnetic stimulation treatment. J Psychopharmacol. 2005;19(3). doi:10.1177/0269881105051545

59. Bae EH, Riviello JJ Jr., Rotenberg A, et al. Safety and tolerability of repetitive transcranial magnetic stimulation in patients with epilepsy: a review of the literature. Epilepsy Behav. 2007;10(4):521-528. doi:10.1016/j.yebeh.2007.03.004
60. Pereira LS, Müller VT, da Mota Gomes M, Rotenberg A, Fregni F. Safety of repetitive transcranial magnetic stimulation in patients with epilepsy: a systematic review. Epilepsy Behav. 2016;57:167-176. doi:10.1016/j.yebeh.2016.01.015

61. Vernet M, Walker L, Yoo W-K, Pascual-Leone A, Chang BS. EEG onset of a seizure during TMS from a focus independent of the stimulation site. Clin Neurophysiol. 2012;123(10):2106-2108. doi:10.1016/j.clinph.2012.03.015

62. Stultz DJ, Osburn S, Burns T, Walton R, Wajswol SP. TMS treatment in a patient with seizures and refractory depression. Brain Stimul. 2019;12(3):791. doi:10.1016/j.brs.2019.08.009

63. Fitzgerald PB. Treatment of depression in a patient with epilepsy. Brain Stimul. 2014;7(4):619-620. doi:10.1016/j.brs.2014.03.003

64. Bagati D, Mittal S, Praharaj SK, Sarcar M, Kakra M, Kumar P. Repetitive transcranial magnetic stimulation safely administered after seizure. JECT. 2012;28(1):60-61. doi:10.1097/YCT.0b013e318221f9b1

65. Stultz DJ. Successful continued TMS treatment after a seizure: a letter to the editor. Brain Stimul. 2019;12(3):791. doi:10.1016/j.brs.2019.01.009

66. Fitzgerald PB, Daskalakis ZJ. A practical guide to the use of repetitive transcranial magnetic stimulation in the treatment of depression. Brain Stimul. 2012;5(3):287-296. doi:10.1016/j. brs.2011.03.006
Neuropsychiatric Disease and Treatment

\section{Publish your work in this journal}

Neuropsychiatric Disease and Treatment is an international, peerreviewed journal of clinical therapeutics and pharmacology focusing on concise rapid reporting of clinical or pre-clinical studies on a range of neuropsychiatric and neurological disorders. This journal is indexed on PubMed Central, the 'PsycINFO' database and CAS, and

\section{Dovepress}

is the official journal of The International Neuropsychiatric Association (INA). The manuscript management system is completely online and includes a very quick and fair peer-review system, which is all easy to use. Visit http://www.dovepress.com/testimonials.php to read real quotes from published authors. 